\title{
1 Modelling the Potential Spread of the Red-billed Leiothrix Leiothrix lutea 2 in Italy
}

3 Samuele Ramellini ${ }^{\mathrm{a}, \mathrm{b}}$, Andrea Simoncinic ${ }^{\mathrm{c}}$, Gentile Francesco Ficetola ${ }^{\mathrm{a}, \mathrm{d}}$, Mattia 4 Falaschi $^{\mathrm{a}}$

$5 \quad{ }^{a}$ Dipartimento di Scienze e Politiche Ambientali, Università degli Studi di Milano, 20133

6 Milano, Italy;

7 b Stazione Romana Osservazione e Protezione Uccelli, 00186 Roma, Italy;

8 'Dipartimento di Biologia, Università di Pisa, 56126 Pisa, Italy;

$9 \quad{ }^{\mathrm{d}}$ Laboratoire d'Écologie Alpine (LECA), University Grenoble Alpes, CNRS, University

10 Savoie Mont Blanc, 38000 Grenoble, France.

11 Corresponding author: Andrea Simoncini simonciniandre@gmail.com 
13 Capsule: The introduced Red-billed Leiothrix can greatly expand its range in Italy, with 14 many regions being at high risk of invasion due to their high habitat suitability.

15 Aims: To assess the environmental variables affecting the distribution of the Red-billed 16 Leiothrix during the invasion process, and to predict the potential distribution of the species 17 in Italy.

18 Methods: We retrieved 548 occurrence data from Liguria (Northern Italy), Tuscany and 19 Latium (Central Italy) using the Ornitho.it portal, a citizen science-based resource. We used 20 species distribution models to assess the most important climatic and landscape variables for 21 the presence of the species and to generate a countrywide habitat suitability map.

22 Results: Leiothrix distribution was jointly affected by climatic and landscape variables, being 23 related to precipitation seasonality, percentage cover of agricultural areas, and annual 24 precipitation. Habitat suitability for the Leiothrix was highest at intermediate levels of 25 precipitation seasonality, decreased with the amount of agricultural areas, and increased with annual precipitation. The results of species distribution models were highly consistent across regions. The areas with the highest suitability for the species occurred in a strip spanning the 28 northern and western sides of Italy, particularly in regions with a Mediterranean climate.

29 Conclusion: Broad areas of Italy have a high risk of invasion by the Red-billed Leiothrix. 30 We provide fine-grained information on the magnitude of habitat suitability over the Italian 31 peninsula. 
Invasive alien species (IAS) have major negative impacts on native communities and promote the homogenization of global floras and faunas (Elton 1958, McKinney \& Lockwood 1999, Nentwig 2007, Primack \& Sher 2018). Moreover, the introduction of IAS influences the economic system of the invaded regions, with often unpredictable outcomes (Pimentel et al. 2005). Predicting the spread of IAS is pivotal for their control (Elith 2017). This, in turn, requires knowledge of the factors determining the establishment and expansion of introduced species. Still, knowledge of the future spread and the processes that drive it is lacking for many alien bird species (Engler et al. 2017).

This study focuses on the Red-billed Leiothrix Leiothrix lutea, a polytypic species belonging to the family of Babblers (Passeriformes, Timaliidae) with an Indo-Malayan primary distribution range (Collar et al. 2017). This Babbler has been frequently released in nature through the pet trade, one of the main introduction pathways of IAS (Richardson 2010, Pârâu et al. 2016). The Leiothrix appears to have species-specific ecological and morphological traits that make it a successful invader across many different regions of the world (Pereira et al. 2017). It has an important impact on biodiversity and has been classified as one of the seven bird IAS with the strongest effects on native biota (Martin-Albarracin et al. 2015), because of competition with native birds and seed dispersion of both native and non-native plant species (Tassin \& Rivière 2001). Its presence as a nonindigenous species has been documented in Japan, Hawaii, and Europe (Collar et al.2017). In Europe, the Leiothrix has established populations in Spain, Portugal, France, and Italy (Lever 2005, Brichetti \& Fracasso 2010; Pereira et al. in press). In Italy, this species is considered a naturalized breeding species (Baccetti et al. 2014, Brichetti \& Fracasso 2015), and has been recorded mainly in Friuli, Latium, Liguria, Tuscany and the Venetian regions, with scattered data from other regions (Spanò et al. 2000, Puglisi et al. 2009, Puglisi et al. 2011, Ramellini 2017, Pereira et al in press). In this country, the species has been spreading since 1980 (Brichetti \& Fracasso 2010) and many reports have been published on its local expansion dynamics (e.g. Verducci 2009, Baghino \& Fasano 2017, Ramellini 2017). Knowledge on the factors affecting Leiothrix distribution is limited to the native range, Japan, Spain and Hawaii (Fisher \& Baldwin 1947, Amano \& Eguchi 2002a, Herrando et al. 2010, Collar et al. 2017), and finescale predictions of its potential expansion are currently restricted to the northeastern Iberian Peninsula (Herrando et al. 2010, but see also Pereira et al in press for a coarse-scale analysis). In Italy, no study has provided information on the factors driving Leiothrix distribution, nor has provided information on its potential countrywide invasion.

In this study, we aimed to: (i) assess the factors driving Leiothrix distribution in Italy, (ii) identify the areas in Italy that suffer the highest invasion risk, by building species distribution models (SDMs, Elith \& Leathwick 2009) with occurrence data from Liguria, Tuscany, and Latium. This knowledge will help to set up appropriate monitoring protocols to prevent further invasions by the Leiothrix in Italy. Given the current knowledge of the habitat preferences of the Leiothrix (e.g. Herrando et al. 2010, Collar et al. 2017, Ramellini 2017) and of the factors that generally drive species distribution (Bradie \& Leung 2017, Bowman et 
al. 2017), we hypothesized that: (i) SDMs applied to Leiothrix would predict an expansion of the species in Italy, (ii) climatic and vegetation variables (cover of broadleaved forest and shrubs) would have a key role in determining the Leiothrix distribution in Italy.

\section{Methods}

\section{Sources of data}

We extracted presence records of Leiothrix at the $1-\mathrm{km}$ resolution from the Ornitho portal (www.ornitho.it). This open-access platform collects georeferenced and validated biodiversity data within Italian national borders and its archives are freely searchable by contributors. We did not consider other portals (e.g. eBird and iNaturalist) as they include a very small number of data for the study species, compared to Ornitho. The use of datasets from citizen science projects has gained momentum in ecology during the last decades (Kobori et al. 2016, Ellwood et al. 2017) and has been successfully employed in invasion biology (e.g. Gallo \& Waitt 2011, Falaschi et al. 2017). The research on the Ornitho portal was performed using the following entries: temporal extent "All the period recorded in the system", species "Red-billed Leiothrix", spatial extent "Regions of Latium, Tuscany, and Liguria", i.e. the three regions in Italy where the species is currently widespread. In compliance with the site's rules, data usage permission was requested via personal communication to the users involved. These data were complemented with our own field records, collected in 2012-2018 in Latium and Liguria. All data were then combined into our final dataset, consisting of 548 georeferenced records, 228 from Liguria, 230 from Tuscany and 90 from Latium. The distribution of records is shown in Figure 1. We assumed that these records represent individuals released in nature from a sufficient amount of time or within already established populations, i.e. we assumed that no records from individuals temporarily recorded in unsuitable habitats existed in our dataset. This assumption is justified by the fact that Leiothrix populations in Liguria and Tuscany originated from a single escape of 80 individuals from an aviary in 1982 (Besagni 2000). In Latium, populations originated from multiple releases between 1998 and 2003, followed by the rapid establishment and spread of Leiothrix naturalized populations (Ramellini 2017).

\section{Environmental variables}

Overall, we considered ten environmental variables, describing landscape (percentage cover of agricultural areas, broadleaved forests, shrubs and bushes, and urban areas; distance from rivers), climatic conditions (total annual precipitation, precipitation seasonality, mean annual temperature, and temperature seasonality), and altitude (Table 2). Moreover, we calculated roads density within the 1-km cell, on the basis of road maps obtained from the Geofabrik OpenStreetMap server (www.geofabrik.de), as it is a major factor determining accessibility and the availability of biodiversity data, particularly in citizen science data (Ficetola et al. 2013, Merow et al. 2016). All variables were at the 1$\mathrm{km}$ resolution. 
112 To obtain land-cover information we used the CORINE Land Cover Map of Europe 113 (European Commission et al.1994), which has been successfully used to model invasion 114 risk (e.g. Ficetola et al. 2010, Polce et al. 2011, Gallien et al. 2012). From this map, we 115 extracted four layers, representing the percentage cover of four different land-cover classes 116 at the 1-km resolution: broadleaved forests, shrubs and bushes, agricultural and urban. The 117 Leiothrix tends to occupy broadleaved forested areas both in the native and in the invaded 118 range (Herrando et al. 2010, Collar et al. 2017, Ramellini 2017). Therefore, we expected 119 that the broadleaved variable would contribute significantly to model performance.

120 Coniferous forests are important in the native range (Collar et al. 2017), but in the native 121 range coniferous woods have a different species composition and dominant growth forms 122 compared to the invaded range (Blasi et al. 2014, Collar et al. 2017). Furthermore, 123 coniferous forests have a negligible cover in the study area. Therefore, this variable was not included in our models. We also considered agricultural and urban cover because human-dominated landscapes have multiple impacts on invasive species (Case 1996, Pârâu et al. 2016). In the case of the Leiothrix, we expected these landscapes to represent unsuitable habitats, given the evidence from other invaded areas (Amano \& Eguchi 2002b, Herrando et al. 2010, Ramellini 2017).

129 We extracted the distance from rivers from a vectorial map of Italian rivers, downloaded 130 from the ISPRA geoportal (www.sinanet.isprambiente.it). This variable was measured as 131 the distance of the centroid of each cell from the nearest cell containing a river.

132 Other studies found that the presence of rivers is a factor influencing the distribution of the 133 Leiothrix, which tends to select nest sites near streams, guided by the greater food 134 availability in freshwater ecosystems (Fisher \& Baldwin 1947, Amano \& Eguchi 2002a). 135 Nesting near rivers could also influence behavioural trade-offs and possibly increases the 136 fitness of the species (Zhang et al. 2016). Moreover, the species could use rivers as 137 pathways for expansion and colonization of new areas (Ramellini 2017).

138 We did not consider variables representing the cover of lakes and wetlands as there is no 139 evidence of Leiothrix preference for these environments.

\section{Climatic variables}

141 Climatic variables are fundamental determinants of the distribution and spread of alien species (Guisan et al. 2017). We retrieved climatic variables at the 1-km scale (average of the period 1979-2013) from the CHELSA Climate dataset (Karger et al. 2017). We considered four climatic variables representing availability and seasonality of water and energy: total annual precipitation, precipitation seasonality, mean annual temperature, and temperature seasonality. Precipitation seasonality and temperature seasonality represent respectively the standard deviation (SD) and the coefficient of variation (CV) of mean monthly values. Precipitation variables are known to be particularly relevant for the species in Japan (Amano \& Eguchi 2002a). Before running the analyses, we measured pairwise correlation between variables (Table S1) and we did not consider altitude for 
analyses because of its strong correlation with the annual mean temperature $(r=0.91)$. The correlations between the other variables were always $<0.7$ (Table S1), suggesting the lack of major collinearity issues (Dormann et al. 2012).

\section{Species distribution modelling}

We used maximum entropy modelling (Maxent; Phillips et al. 2006) to assess relationships between Leiothrix distribution and environmental variables. Maxent is among the most widely used methods in species distribution modelling (Gomes et al. 2018). It makes use of presence/background data and is, therefore, highly suitable to model citizen science data, with an excellent performance among the SDM approaches (Elith et al. 2006, Elith et al. 2011, Peterson et al. 2011). Engler et al. (2017), in a review about SDM in birds, showed that models of this kind help to gain a better insight into the processes underlying the spread of IAS. Furthermore, Maxent is among the models with the highest transferability, i.e. it has excellent performance in predicting suitability outside the calibration areas (Qiao et al. 2019).

\section{Model settings}

When assessing relationships between species occurrence and environmental variables, we only considered linear and quadratic terms to avoid overfitting (Phillips et al. 2006, Herrando et al. 2010). Areas that are easily accessible or better surveyed are spatially biased (Phillips et al. 2006, Ficetola et al. 2013), so that some areas can be overrepresented or underrepresented (Phillips et al. 2009, Kramer-Schadt et al. 2013). In our analyses, we assumed that areas with a higher density of roads were more frequently sampled and thus overrepresented in our models. We, therefore, included the variable "roads density" as a bias file in all our models, both for the background and the sampled areas (Kramer-Schadt et al. 2013). Species distribution models require the selection of background data or pseudo-absences within a buffer zone defined around all the presence-points, representing areas that are actually accessible to the study species (Phillips et al.2009, Godsoe 2010), thus our background points were obtained within a buffer of $100 \mathrm{~km}$ from the presence records (Gallien et al. 2012). Within the buffer (Figure 1), we excluded points outside Italy and in marine areas.

\section{Modelling workflow and accuracy tests}

We followed a modelling workflow aimed at maximizing the robustness of predictions while minimizing the impacts of sampling bias (Nogués-Bravo 2009, Bahn \& McGill 2013). We considered occurrences of the Leiothrix from Tuscany and Liguria as belonging to a single group of populations as, even if individuals originated from different escape events, populations are currently merged (Figure 1). Therefore, we aggregated data from Liguria and Tuscany, and we considered data from Latium as part of an independent population. We ran separate models for each of the two study populations, using the second population as a test dataset to assess model performance. First, we built SDMs using the Liguria-Tuscany data for training and used the Latium for model validation. Second, we built SDMs using the Latium data for training and used the Liguria-Tuscany data for model validation. The validation in a 
different study area is among the most robust tests of model performance (e.g. Nogués-Bravo 2009, Bahn \& McGill 2013, Galante et al. 2017). To test the overall accuracy of predictions we used the area under the receiver operating characteristic curve (AUC), a frequently employed threshold-independent measure in ecological modelling (Guisan \& Zimmermann 2000; for an example of its use with this species see Herrando et al. 2010). AUC values range from 0.5 (random output) to 1 (optimal performance). It should be remarked though that the maximum achievable AUC of Maxent models is below 1 (Phillips et al. 2006). AUC was run on both the training dataset and the test dataset, to assess the model consistency across areas. For each region we ran three models: one with landscape variables only, one considering climatic variables only, and one considering all the variables. We then used the AUC on the validation dataset to assess the predictive performance of each model.

\section{Full model}

In order to obtain a model representing the overall habitat selected by the species in Italy, we ran a model (hereafter full model), considering all the presence records and both climatic and landscape variables. Given the lack of a validation dataset for the full model, the robustness of the model was assessed using a 5-fold cross-validation (Nogués-Bravo 2009). The average model among the cross-validated ones was then projected to the whole Italy, to identify the areas most at risk of invasion outside the study regions. In SDM, extrapolations beyond the range of environmental variables observed in the training area may determine unreliable results. Therefore, we computed multidimensional environmental similarity surfaces and identified areas where SDM extrapolated onto environmental conditions that are outside the ones observed within the training range (Elith et al. 2010, Masin et al. 2014).

\section{Results}

When using Latium as training and Liguria-Tuscany as test dataset, the model including both climate and landscape variables showed the highest performance (Table 1), outperforming models including climate only and landscape only. The model including both climate and landscape was the best one also when calibrated on the Liguria-Tuscany data. Both the model calibrated on the Latium data, and the model calibrated on the Liguria-Tuscany data, showed a good ability to predict the test dataset of the other region, suggesting robustness of the model (Table 1).

\section{Leiothrix potential distribution}

By projecting the full model to the whole Italy, we identified two main areas with high suitability for the Leiothrix: (i) a band of medium/high suitability stretching from the western corner of Liguria (NW Italy) to the Tyrrhenian side of Calabria (Southern tip of continental Italy) and (ii) in lowland and hilly areas of Northern Italy, immediately South of the Alps (Figure 2). In Sardinia and in portions of Sicily, Calabria, Apulia, and Northern Italy, environmental conditions were mostly outside the range found in the calibration range, thus predictions were not considered for these regions (Figure 2). 
228

229

230

231

232

233

234

235

236

237

238

239

240

241

242

243

244

245

246

247

248

249

250

251

252

253

254

255

256

257

258

259

260

261

262

263

264

When we built the full model, precipitation seasonality, percentage of agricultural cover, annual mean temperature, and temperature seasonality were the most important variables in terms of percentage contribution to explain Leiothrix distribution. Distance from the nearest river, broadleaved cover, and percentage cover of urban areas had limited importance (Table 2). Leiothrix suitability was highest in areas with low agricultural cover, high annual precipitation, and intermediate precipitation seasonality (Figure 3). Furthermore, suitability was highest in areas with high annual mean temperature (Figure $3 b$ ).

\section{Discussion}

Our results showed that a further expansion of the Leiothrix in Italy is likely on the northern and western sides of the peninsula, in agreement with our hypothesis that this species has the potential to attain a wider distribution in Italy. We provided indications on the factors that could shape Leiothrix expansion and confirmed the joint importance of climate and landscape variables to understand the distribution of this species (cfr. Bradie \& Leung 2017). Some regions where the species is known to occur outside Liguria, Latium, and Tuscany, for instance, the Northeastern area of Piedmont (Grimaldi 1992), were correctly predicted as suitable from the full model.

\section{Climatic variables}

Climatic variables were very important to explain the Leiothrix distribution, in agreement with the hypothesis that these factors are key drivers of the spread of invasive birds (Pereira et al. in press, Table 2). Our work suggests that rain regimes in the invaded region can significantly affect the distribution in this species (Table 2). The response curve for annual precipitation showed the highest suitability in areas with precipitation $>1000 \mathrm{~mm} /$ year, i.e. values higher than those typical for a Mediterranean climate (Allaby 2015). Such match with high precipitation values is in agreement with observations from Leiothrix invasion in Japan and other areas of Europe (Amano \& Eguchi 2002a, Pereira et al. in press) and is not unexpected given that the species is also native of rainy regions of China (Zhang et al. 2016). When discussing the factors influencing the Leiothrix invasion in the Hawaiian Islands, Fisher \& Baldwin (1947) considered rainfall to be "apparently" not a determining factor. However, it should be remarked that in Hawaii average precipitation are much higher than in Mediterranean regions, and thus they are probably not a limiting factor. As precipitation seasonality influences plant diversity in Mediterranean ecosystems (Clary 2008), the preference of the species for intermediate values of precipitation seasonality might be related to association with particular plant communities. The response curve for annual mean temperature indicated higher suitability at increasing values of temperature, highlighting a preference of the Leiothrix for warmer climates. In our suitability map, the majority of the cells with the highest suitability fell within areas characterized by a Mediterranean climate. The establishment of self-sustaining populations of Leiothrix across other areas with a 

press), suggesting that in its European range the species can occupy niches different from the native ones. This process can be due to niche unfilling of the species (cfr. Petitpierre et al. 2012, Strubbe et al. 2013), and additional studies are required to evaluate these hypotheses.

\section{Landscape variables}

270 Among the landscape variables, agriculture showed the highest importance in explaining the

271

272

273

274

275

276

277

278

279

280

281

282

283

284

285

286

287

288

289

290

291

292

293

294

295

296

297

298

299

300

301

302

303

304

Leiothrix distribution. Suitability decreased in the areas with highest agricultural cover, in accordance with previous studies in Italy and in other invaded areas, where the species tends to occupy rather natural, undisturbed habitats (Amano \& Eguchi 2002b, Herrando et al. 2010, Ramellini 2017). This is in contrast with the general pattern shown by bird IAS which are often associated to open and disturbed habitats (Case 1996, Duncan et al. 2003, see also Pereira et al. in press). In our study, distance from the nearest river showed minor importance compared to the other variables. This result could be explained considering that we did not focus on the nesting period, which was the focus of some previous studies underlining the importance of water ecosystems for the species (Zhang et al. 2016). Furthermore, our analysis was performed at a rather coarse scale $(1-\mathrm{km})$ : it is possible that we did not capture processes occurring at the microhabitat level (e.g. small streams). The cover by broadleaved forests showed a limited importance. This result is not in agreement with our second hypothesis, nor with studies suggesting that forests are a key driver of Leiothrix distribution (Herrando et al. 2010). This could occur because of the differences between the two areas used to calibrate the models, and because of differences in forest composition that are not captured by broad-scale habitat maps, which are not able to distinguish among typologies of broadleaved forests with different composition or tree density. Advances of remote sensing techniques promise great improvements of our ability to measure habitat at high resolution and could allow to better describe fine-scale habitat variation, thus allowing enhanced understanding of species distribution (Ficetola et al. 2014).

\section{Outlook}

Our results provide fine-grained, baseline information for the prevention of Leiothrix colonization in uninvaded areas. They can also contribute to drawing up management plans for the species both at the local and national levels. Our study further highlights the importance of developing SDMs to assess the invasive potential of IAS. Given the high invasive potential of this Babbler, and the strong known impacts on native species (MartinAlbarracin et al. 2015), we suggest its possible inclusion in the list of alien species of European concern (Regulation EU No. 1143/2014). For a proper interpretation of SDMs results and for the definition of future lines of research it is necessary to acknowledge the limitations and assumptions of each modelling technique (Ficetola et al. 2010, Araújo \& Peterson 2012, Engler et al. 2017, Barbet-Massin et al. 2018). In our work, we assumed a constant land-use and climate through time as we did not consider historical variations in the environmental conditions. Dynamically modelling the distribution of the species could help in refining our predictions (Brambilla et al. 2010). As we did not take into account variations 
305 in the species distribution, possible future lines of research could be aimed at defining past 306 patterns of invasion to better understand invasion dynamics and extrapolate further 307 predictions (Ficetola et al. 2010). The information we provide could be profitably combined 308 with studies employing connectivity, in order to evaluate the potential spread of the Leiothrix 309 while integrating information on landscape connectivity and to identify potential corridors of 310 invasion (e.g. Cowley et al. 2015, Falaschi et al. 2017). Future work should also be done to 311 refine our knowledge on the environmental conditions that favour the species in the 312 Mediterranean region at a finer spatial scale, e.g. an in situ evaluation of population growth 313 rates could help to define the population-persistence niche for this Babbler. 


\section{Acknowledgments:}

315 We thank all the observers who provided data and we especially thank N. Bonassin, M. 316 Coppola, E. Mori, R. Nardelli, and G. Tellini Florenzano for providing clustered data, P.

317 Ramellini E. Mori for comments on the text, D. Rubolini, A. Galimberti, and M. Bertoncini

318 for technical advice. We are also grateful to the anonymous reviewers for their helpful 319 comments on the manuscript. 
320 We have no conflicts of interest to disclose. 
322

323

324

325

326

327

328

329

330

331

332

333

334

335

336

337

338

339

340

341

342

343

344

345

346

347

348

349

350

351

352

353

354

355

356

357

358

359

360

361

362

Allaby, M. (ed.) 2015. A Dictionary of Ecology (5 ed.). Oxford University Press, Oxford. Amano, E.H \& Eguchi, K. 2002a. Nest-site selection of the Red-Billed Leiothrix and Japanese Bush Warbler in Japan. Ornithol. Sci. 1: 101-110.

Amano, E.H. \& Eguchi, K. 2002b. Foraging niches of introduced Red-billed Leiothrix and native species in Japan. Ornithol. Sci. 1: 123-131.

Araújo, M.B. \& Peterson, A.T. 2012. Uses and misuses of bioclimatic envelope modeling. Ecology 93: 1527-1539. doi: https://doi.org/10.1890/11-1930.1.

Baccetti, N., Fracasso, G. \& Gotti, C. 2014. La lista CISO-COI degli uccelli italiani - Parte seconda: le specie naturalizzate (cat. C) e le categorie "di servizio" (cat. D, E, X). Avocetta 38: $1-21$.

Baghino, L. \& Fasano, S.G. 2017. La distribuzione dell'usignolo del Giappone Leiothrix lutea in Liguria. Tichodroma 6: 146.

Bahn, V. \& McGill, B.J. 2013. Testing the predictive performance of distribution models. Oikos 122: 321-331.

Barbet-Massin, M., Rome, Q., Villemant, C. \& Courchamp, F. 2018. Can species distribution models really predict the expansion of invasive species? PLOS ONE 13(3): e0193085. doi: https://doi.org/10.1371/journal.pone.0193085.

Blasi, C., Capotorti, G., Copiz, R., Guida, D., Mollo, B., Smiraglia, D. \& Zavattero, L. 2014. Classification and Mapping of the Ecoregions of Italy. Plant Biosyst. 148: 1255-1345. Bowman, W.D., Hacker, S.D. \& Cain, M.L. 2017. Ecology (4 ed.). Oxford University Press, Oxford.

Besagni, I. 2000. Analisi della diffusione in natura di una specie alloctona: 1'Usignolo del Giappone (Leiothrix lutea), nell'entroterra di Sestri Levante (Genova). Thesis presented at the "Università degli studi di Genova" in the academic year 1999-2000.

Bradie, J. \& Leung, B. 2017. A quantitative synthesis of the importance of variables used in MaxEnt species distribution models. J. Biogeogr. 44: 1344-1361.

Brambilla, M., Casale, F., Bergero, V., Bogliani, G., Crovetto, M.G., Falco, R., Roati, M. \& Negri, I. 2010. Glorious past, uncertain present, bad future? Assessing effects of landuse changes on habitat suitability for a threatened farmland bird species. Biol. Conserv. 143: 2770-2778.

Brichetti, P. \& Fracasso, G. 2010. Ornitologia italiana, Vol. 6 - SylviidaeParadoxornithidae. Oasi Alberto Perdisa, Bologna.

Brichetti, P. \& Fracasso, G. 2015. Check-list degli uccelli italiani aggiornata al 2014. Riv. ital. Orn. 85: 31-50.

Case, T. J. 1996. Global patterns in the establishment and distribution of exotic birds. Biol. Conserv. 78: 69-96.

Clary, J. 2008. Rainfall seasonality determines annual/perennial grass balance in vegetation of Mediterranean Iberian. Plant Ecol. 195: 13-20.

Cowley, D.J., Johnson, O. \& Pocock, M.J.O. 2015. Using electric network theory to model the spread of oak processionary moth, Thaumetopoea processionea, in urban woodland patches. Landscape Ecol. 30: 905-918. 
Collar, N., Robson, C. \& de Juana, E. 2017. Red-billed Leiothrix (Leiothrix lutea). In del Hoyo, J., Elliott, A., Sargatal, J., Christie, D. A. \& de Juana, E. (eds) Handbook of the birds of the world alive. Lynx Edicions, Barcelona. (downloaded from http://www.hbw.com/node/59657 on $11^{\text {th }}$ January 2017).

Dubois, P.J. 2007. Les oiseaux allochtones en France: statut et interactions avec les espèces indigènes. Ornithos 14: 329-364.

Duncan, R.P., Blackburn, T.M. \& Sol, D. 2003. The Ecology of Bird Introductions. Annu. Rev. Ecol. Evol. S. 34: 71-98.

Dormann, C.F., Elith, J., Bacher, S., Buchmann, C., Carl, G., Carré, G., Garcia, J.R.M., Bernd, G., Lafourcade, B., Leitão, P.J., Munkemüller, T., McClean, C., Osborne, P.E., Reineking, B., Schröder, B., Skidmore, A.K., Zurell, D. \& Lautenbach, S. 2012. Collinearity: A review of methods to deal with it and a simulation study evaluating their performance. Ecography 36: 27-46.

Elith, J., Graham, C.H., Anderson, R.P., Dudík, M., Ferrier, S., Guisan, A., Hijmans, R.J., Huettmann, F., Leathwick, J.R., Lehmann, A., Li, J., Lohmann, L.G., Loiselle, B.A., Manion, G., Moritz, C., Nakamura, M., Nakazawa, Y., Overton, J.M., Peterson, A.T., Phillips, S.J., Richardson, K.S., Scachetti-Pereira, R., Schapire, R.E., Soberon, J., Williams, S., Wisz, M.S. \& Zimmermann, N.E. 2006. Novel methods improve prediction of species' distributions from occurrence data. Ecography 29: 129-151.

Elith, J. \& Leathwick, J. R. 2009. Species Distribution Models: Ecological Explanation and Prediction Across Space and Time. Annu. Rev. Ecol. Evol. S. 40: 677-697.

Elith, J., Kearney, M. \& Phillips, S. 2010. The art of modelling range-shifting species. Methods Ecol. Evol. 1: 330-342.

Elith, J., Phillips, S.J., Hastie, T., Dudík, M., Chee, Y.E. \& Yates, C.J. 2011. A statistical explanation of MaxEnt for ecologists. Divers. Distrib. 17: 43-57.

Elith, J. 2017. Predicting distributions of invasive species. In Robinson, P.A., Walshe, T., Burgman, M., Nunn, M. (ed) Invasive Species. Risk Assessment and Management: 93-129. Cambridge University Press, Cambridge.

Ellwood, E., Crimmins, T. \& Miller-Rushing, A. (ed.) 2017. The role of citizen science in biological conservation. Biol. Conserv. 208: 1-188.

Elton, C.S. 1958. The Ecology of Invasions by Animals and Plants. Chapman \& Hall, London.

Engler, J.O., Stiels, D., Schidelko, K., Strubbe, D., Quillfeldt, P. \& Brambilla, M. 2017. Avian SDMs: current state, challenges and opportunities. J. of Avian Biol. 48: 1483-1504. European Commission, European Environment Agency and European Topic Centre on Land Cover. 1994. CORINE land cover. Technical guide. Commission of the European Communities, Luxembourg.

Falaschi, M., Mangiacotti, M., Sacchi, R., Scali, S. \& Razzetti, E. 2017. Electric circuit theory applied to alien invasions: a connectivity model predicting the Balkan frog expansion in Northern Italy. Acta Herpetol. 13: 33-42.

Ficetola, G.F., Bonardi, A., Mucher, C.A., Gilissen, N.L.M. \& Padoa-Schioppa, E. 2014. How many predictors in species distribution models at the landscape scale? Land use versus LiDAR-derived canopy height. Int. J. Geogr. Inf. Sci. 28: 1723-1739. 
406

407

408

409

410

411

412

413

414

415

416

417

418

419

420

421

422

423

424

425

426

427

428

429

430

431

432

433

434

435

436

437

438

439

440

441

442

443

444

445

446

447

448

449

Ficetola, G.F., Bonardi, A., Sindaco, R., Padoa-Schioppa, E. 2013. Estimating patterns of reptile biodiversity in remote regions. J. Biogeogr. 40: 1202-1211.

Ficetola, G.F., Maiorano, L., Falcucci, A., Dendoncker, N., Boitani, L., Padoa-

Schioppa, E., Miaud, C. \& Thuiller, W. 2010. Knowing the past to predict the future: landuse change and the distribution of invasive bullfrogs. Glob. Change Biol. 16: 528-537.

Fisher, H.I. \& Baldwin, P.H. 1947. Notes on the Red-billed Leiothrix in Hawaii. Pac. sci. 1: 45-51.

Galante Peter, J., Alade, B., Muscarella, R., Jansa Sharon, A., Goodman Steven, M. \& Anderson Robert, P. 2017. The challenge of modeling niches and distributions for datapoor species: a comprehensive approach to model complexity. Ecography 41: 726-736.

Gallien, L., Douzet, R., Pratte, S., Zimmermann, N.E. \& Thuiller, W. 2012. Invasive species distribution models - how violating the equilibrium assumption can create new insights. Global Ecol. Biogeogr. 21: 1126-1136.

Gallo, T. \& Waitt, D. 2011. Creating a Successful Citizen Science Model to Detect and Report Invasive Species. BioScience 61: 459-465.

Gomes, V.H.F., I Jff, S.D., Raes, N., Leão Amaral, I., Salomão, R.P., de Souza Coelho, L., et al. 2018. Species distribution modelling: contrasting presence-only models with plot abundance data. Sci. Rep. 8: 1003.

Godsoe, W. 2010. I can't define the niche but I know it when I see it: a formal link between statistical theory and the ecological niche. Oikos 119: 53-60.

Grimaldi, P. 1992. Osservazioni sull'Usignolo del Giappone Leiothrix lutea allo stato libero a Verbania Pallanza (NO). Picus 18: 35-36.

Guisan, A. \& Zimmermann, N.E. 2000. Predictive habitat distribution models in ecology. Ecol. Model. 135: 147-186.

Guisan, A., Thuiller, W., \& Zimmermann, N. 2017. Habitat Suitability and Distribution Models: With Applications in R. Cambridge University Press, Cambridge.

Herrando, S., Llimona, F., Brotons, L. \& Quesada, J. 2010. A new exotic bird in Europe: recent spread and potential range of Red-billed Leiothrix Leiothrix lutea in Catalonia (northeast Iberian Peninsula). Bird Study 57: 226-235.

Kramer-Schadt, S., Niedballa, J., Pilgrim, J.D., Schröder, B., Lindenborn, J., Reinfelder, V., Stillfried, M., Heckmann, I., Scharf, A.K., Augeri, D.M., Cheyne, S.M., Hearn, A.J., Ross, J., Macdonald, D.W., Mathai, J., Eaton, J., Marshall, A.J., Semiadi, G., Rustam, R., Bernard, H., Alfred, R., Samejima, H., Duckworth, J.W.,

Breitenmoser-Wuersten, C., Belant, J.L., Hofer, H. \& Wilting, A. 2013. The importance of correcting for sampling bias in MaxEnt species distribution models. Divers. Distrib. 19: 1366-1379.

Kobori, H., Dickinson, L.J., Sakurai, R.W.I., Amano, T., Komatsu, N., Kitamura, W., Koyama, S.T.K., Ogawara, T. \& Miller-Rushing, J.A. 2016. Citizen science: a new approach to advance ecology, education, and conservation. Ecol. Research 31: 1-19. Karger, D.N., Conrad, O., Böhner, J., Kawohl, T., Kreft, H., Soria-Auza, R.W., Zimmermann, N.E., Linder, H.P. \& Kessler, M. 2017. Climatologies at high resolution for the earth's land surface areas. Scientific Data 4: 170122. doi: https://doi.org/10.1038/sdata.2017.122.

Lever, C. 2005. Naturalised birds of the World. T. \& A. D. Poyser, London. 

Non-Native Birds on Native Ecosystems: A Global Analysis. PLoS ONE 10: e0143070. doi: 10.371/journal.pone.0143070.

Masin, S., Bonardi, A., Padoa Schioppa, E., Bottoni, L. \& Ficetola, G.F. 2014. Risk of invasion by frequently traded freshwater turtles. Biol. Invasions 16: 217-231.

McKinney, M.L. \& Lockwood, J.L. 1999. Biotic homogenization: a few winners replacing many losers in the next mass extinction. Trends Ecol. Evol. 14: 450-453.

Merow, C., Allen, J.M., Aiello-Lammens, M. \& Silander, J.A. 2016. Improving niche and range estimates with Maxent and point process models by integrating spatially explicit information. Global Ecol. Biogeogr. 25: 1022-1036.

Nentwig, W. 2007. Biological Invasions: why it matters. In Nentwig, W. (ed) Biological Invasions: 1-6. Springer-Verlag, Berlin Heidelberg.

Nogués-Bravo, D. 2009. Predicting the past distribution of species climatic niche. Global Ecol. Biogeogr. 18: 521-531.

Pârâu, L.G., Strubbe, D., Mori, E., Menchetti, M., Ancillotto, L., van Kleunen, A., White, R.L., Luna, A., Hernández-Brito, D., Le Louarn, M., Clergeau, P., Albayrak, T., Detlev, F., Braun, M.P., Schroeder, J. \& Wink, M. 2016. Rose-ringed Parakeet Psittacula krameri Populations and Numbers in Europe: A Complete Overview. The Open Ornithology Journal 9: 1-13.

Pereira, P.F., Godinho, C., Vila-Viçosa, M.J., Gama Mota, P. \& Lourenço, R. 2017. Competitive advantages of the red-billed leiothrix (Leiothrix lutea) invading a passerine community in Europe. Biol. Invasions 19(5): 1421-1430.

Peterson, T.A., Soberón, J., Pearson, R.G., Anderson, R.P, Martínez-Meyer, E., Nakamura, M. \& Bastos Araújo, M. 2011. Ecological Niches and Geographic Distributions. Princeton University Press, Princeton.

Petitpierre, B., Kueffer, C., Broennimann, O., Randin, C., Daehler, C. \& Guisan, A. 2012. Climatic niche shifts are rare among terrestrial plant invaders. Science 335: 13441348.

Phillips, S.J, Anderson, R.P. \& Schapire, R.E. 2006. Maximum entropy modelling of species geographic distributions. Ecol. Model. 190: 231-259.

Phillips, S.J., Dudík, M., Elith, J., Graham, C.H., Lehmann, A., Leathwick, J. \& Ferrier, S. 2009. Sample selection bias and presence-only distribution models: Implications for background and pseudo-absence data. Ecol. Appl. 19: 181-197.

Pimentel, D., Zuniga, R. \& Morrison, D. 2005. Update on the environmental and economic costs associated with alien-invasive species in the United States. Ecol. Econ. 52: 273-288.

Polce, C., Kunin, W.E., Biesmeijer, J.C., Dauber, J., Phillips, O.L. \& The ALARM Field Site Network. 2011. Alien and native plants show contrasting responses to climate and land use in Europe. Global Ecol. Biogeogr. 20: 367-379.

Primack, R. \& Sher, A.A. 2018. An Introduction to Conservation Biology. Oxford University Press, Oxford.

Puglisi, L., Bosi, E., Corsi, I., Del Sere, M., Pezzo, F., Sposimo, P. \& Verducci, D. 2009. Usignolo del Giappone, bengalino \& Co: alieni in Toscana. Alula 16: 426-431. 
497 Ramellini, S. 2017. L'Usignolo del Giappone Leiothrix lutea nel Lazio: Aggiornamento 498 della distribuzione ed annotazioni eco-etologiche. Alula 24: 95-108.

499 Richardson, D.M. (ed) 2010. Fifty Years of Invasion Ecology: the legacy of Charles Elton. 500 Blackwell Publishing Ltd., Oxford.

501 Spanò, S., Paganini, D., Besagni, I., Galli, L. \& Truffi, G. 2000. Segnalazione di una 502 popolazione naturalizzata di Usignolo del Giappone, Leiothrix lutea (Scopoli, 1786), nella

503 Liguria orientale. Riv. Ital. Orn. 70: 183-185.

504 Strubbe, D., Broennimann, O., Chiron, F. \& Matthysen, E. 2013. Niche conservatism in 505 non-native birds in Europe: niche unfilling rather than niche expansion. Global Ecol.

506 Biogeogr. 22: 962-970.

507 Tassin, J. \& Rivière, J.N. 2001. The potential role of Red-billed Leiothrix Leiothrix lutea 508 on germination of invasive alien plants on Reunion Island (Indian Ocean). Alauda 69: 381509385.

510 Verducci, D. 2009. Analisi preliminare sulla presenza di una popolazione naturalizzata di

511 Usignolo del Giappone Leiothrix lutea (Scopoli, 1786) nella Toscana Nord Occidentale.

512 U.D.I. 34: 95-97.

513 Zhang, Z., Hou, D., Xun, Y., Zuo, X., Yang, D. \& Zhang, Z. 2016. Nest-site microhabitat

514 association of red-billed leiothrix in subtropical fragmented forest in central China: evidence 515 for a reverse edge effect on nest predation risk? J. Nat. Hist. 50: 1483-1501. 


\begin{tabular}{|c|c|c|c|c|}
\hline Training region & Test region & Variables & $\begin{array}{l}\text { Training } \\
\text { AUC }\end{array}$ & $\begin{array}{l}\text { Test } \\
\text { AUC }\end{array}$ \\
\hline Liguria + Tuscany & Latium & Climate & 0.884 & 0.644 \\
\hline Liguria + Tuscany & Latium & Landscape & 0.742 & 0.534 \\
\hline Liguria + Tuscany & Latium & Climate + landscape & 0.900 & 0.646 \\
\hline Latium & Liguria + Tuscany & Climate & 0.929 & 0.690 \\
\hline Latium & Liguria + Tuscany & Landscape & 0.736 & 0.602 \\
\hline Latium & Liguria + Tuscany & Climate + landscape & 0.941 & 0.704 \\
\hline $\begin{array}{l}\text { Liguria }+ \text { Latium }+ \\
\text { Tuscany }\end{array}$ & - & Climate + landscape & - & 0.873 \\
\hline
\end{tabular}

517 Performance of models calibrated on the two training regions, using all the data. For the 518 model calibrated with all the data, the test AUC is the average of test AUC in 5 cross519 validated models. 
Table 2.

\begin{tabular}{lll}
\hline Name & Variable & \% Contribution \\
\hline Bio15 & Precipitation seasonality & 32.52 \\
Agricultural & Percentage cover of agricultural areas & 28.29 \\
Bio1 & Annual mean temperature & 14.13 \\
Bio4 & Temperature seasonality & 10.39 \\
Bio12 & Annual precipitation & 8.43 \\
Heterogeneous & Percentage cover of shrubs and bushes & 3.09 \\
Urban & Percentage cover of urban areas & 1.98 \\
Broadleaved & Percentage cover of broadleaved forests & 1.17 \\
Distance from rivers & Distance from the nearest river & 0.0003 \\
\hline
\end{tabular}

521 Environmental variables considered in the species distribution models, and percentage 522 contribution of the variables in the average model. 
523 Figure 1. Distribution of the occurrence points used for building species distribution models 524 in Italy. Black lines indicate the region from which the background points were selected.

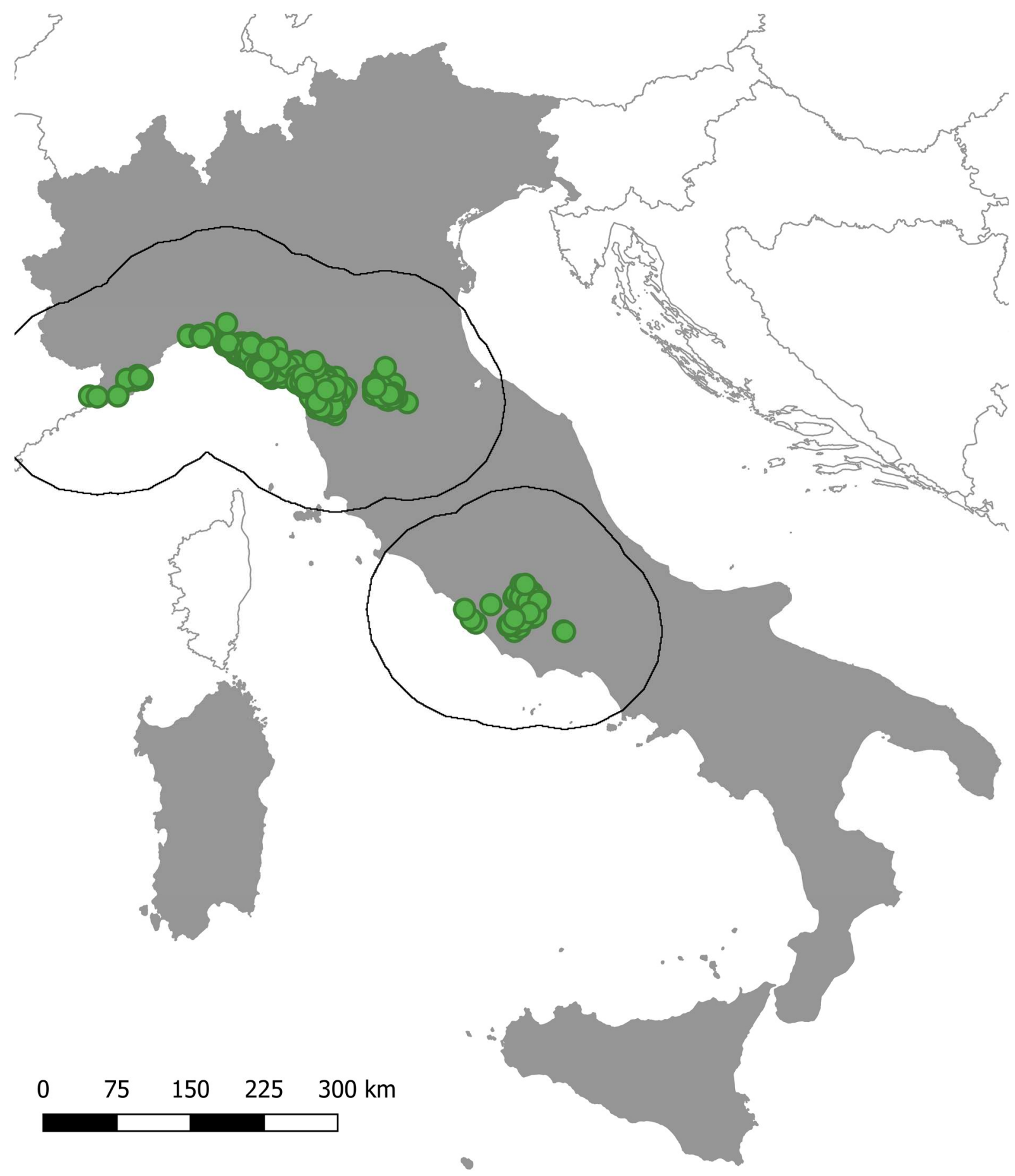


526 Figure 2. Habitat suitability map for Leiothrix lutea in Italy. Suitability thresholds are set at 527 the minimum training presence threshold (0.02) and at the 10-percentile training of the 528 presence threshold. Barred areas represent regions where the model is extrapolated outside 529 the conditions present in the calibration area.

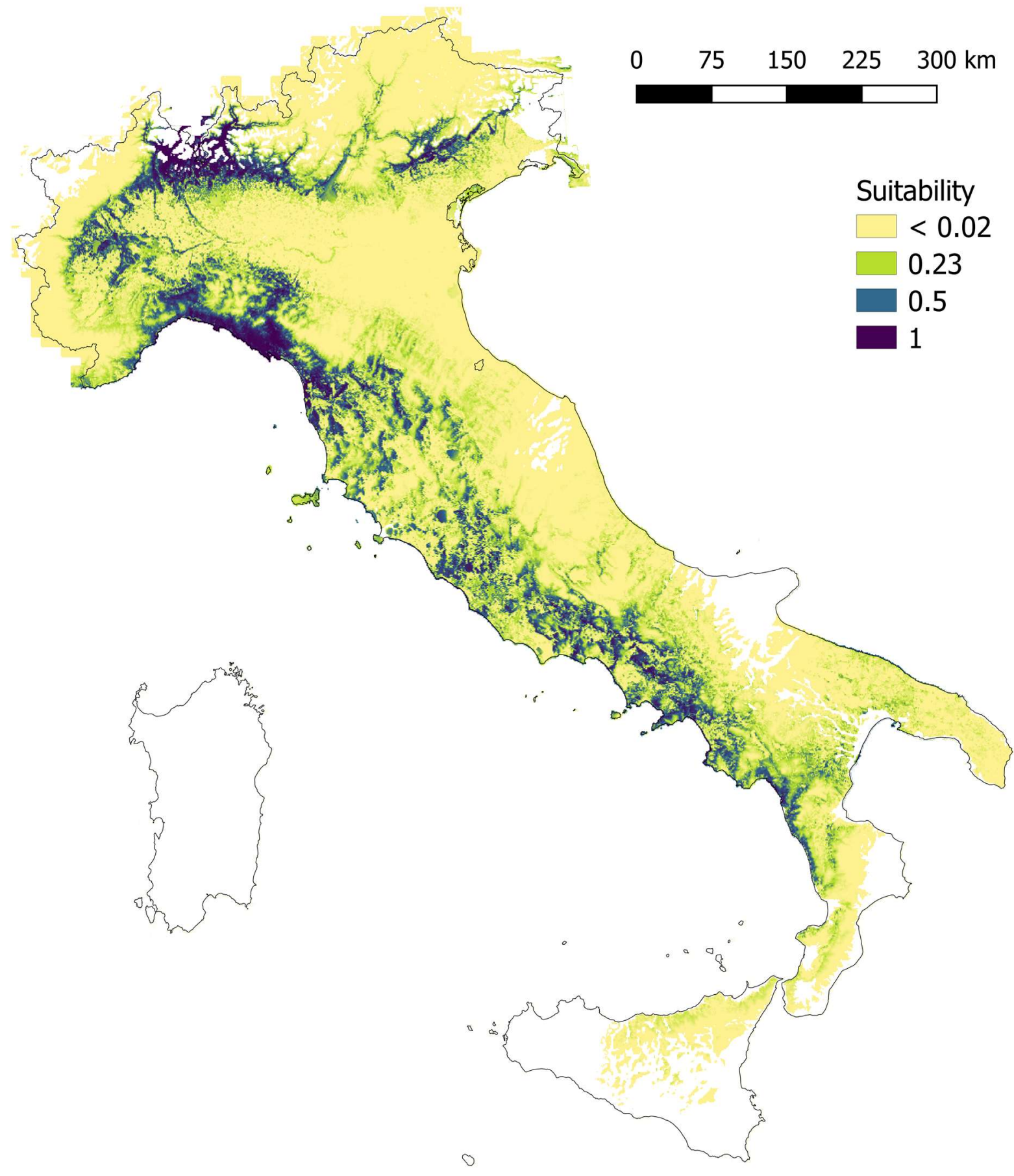


531 Figure 3. Response curves showing the relationship between environmental variables and 532 suitability (in logistic output) for Leiothrix lutea: b-e) climatic variables; a, f, g, i) land-use 533 variables; h) distance from rivers. For each graph, the grey shades represent one standard 534 deviation computed on the basis of a 5-fold cross-validation.
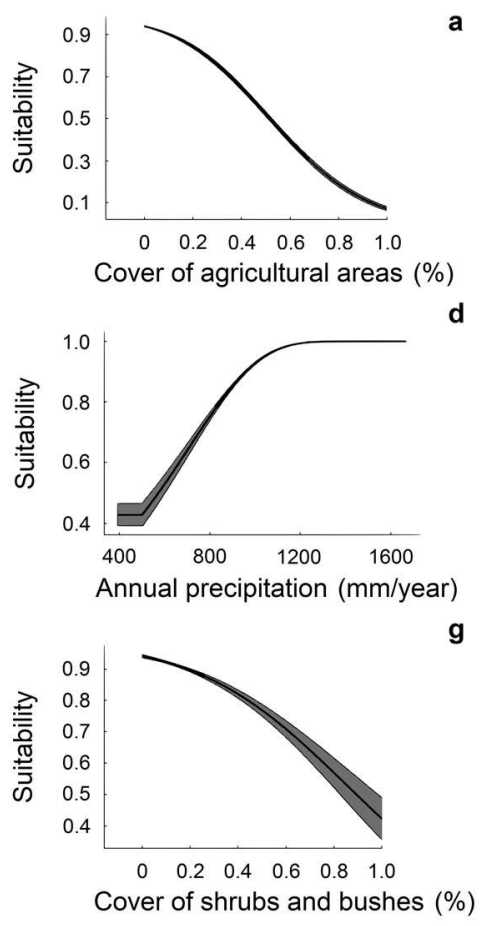

$$
\text { (1) }
$$
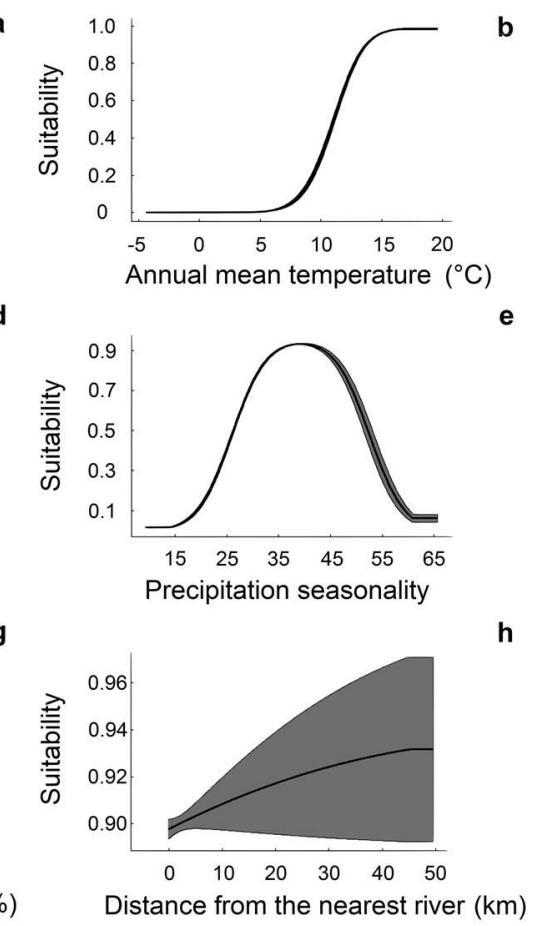

b
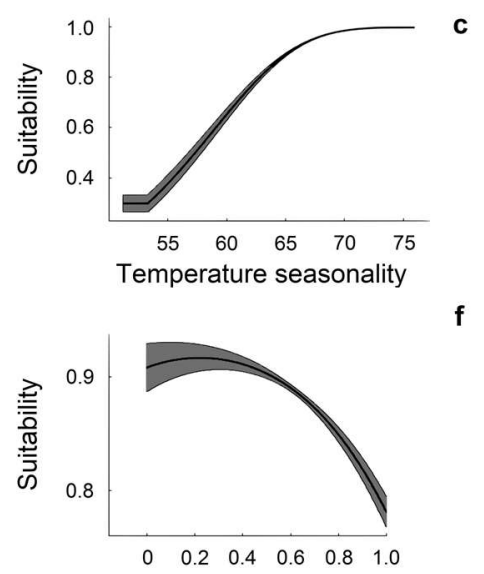

$h$

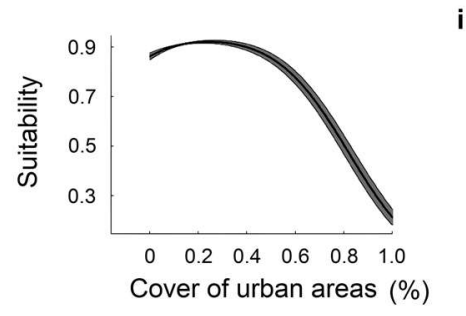

